\title{
ID-Migraine ${ }^{\mathrm{TM}}$ questionnaire and accurate diagnosis of migraine
}

\author{
Questionário ID-Migraine ${ }^{\mathrm{TM}}$ e o adequado diagnóstico da migrânea \\ Ana Carolina Musser Tavares de Mattos ${ }^{1}$, Jano Alves de Souza ${ }^{1,2}$, Pedro Ferreira Moreira Filho ${ }^{1,2}$, \\ Mauro Eduardo Jurno 1,3, Luis Guilhermo Coca Velarde ${ }^{4}$
}

\begin{abstract}
Objective: To analyze the applicability of the Portuguese version of ID-Migraine ${ }^{\mathrm{TM}}$ in a sample of Brazilian patients. Methods: Patients with headache were recruited from the neurology outpatient clinic of a tertiary hospital and submitted to the ID-Migraine ${ }^{\mathrm{TM}}$ questionnaire. The diagnosis of headache was made according to the ICHD-2 criteria. Results: Of the 232 patients, $86 \%$ had migraine. The questionnaire showed a sensitivity of $92 \%(95 \% \mathrm{Cl}, 88 \%$ to $95 \%)$, specificity of $60 \%$ (95\% Cl, $43 \%$ to $77 \%)$ and a positive predictive value of $93 \%$ ( $95 \% \mathrm{Cl}, 89 \%$ to $96 \%$ ). Discussion: Our results were similar to other international studies of the ID-Migraine ${ }^{\mathrm{TM}}$ application. The Portuguese version is considered easy to use, and an appropriate screening tool for migraine diagnosis in our sample. Conclusion: Considering the characteristics of our health system, we can infer that this questionnaire would be beneficial in a Brazilian primary care setting; however, more studies are necessary.
\end{abstract}

Keywords: migraine disorders; surveys and questionnaires; headache.

\section{RESUMO}

Objetivo: Analisar a aplicabilidade da versão em Português do ID-Migraine ${ }^{\mathrm{TM}}$ em uma amostra de pacientes brasileiros. Métodos: Pacientes com cefaleia foram recrutados no Ambulatório de Neurologia de um hospital terciário e submetidos ao questionário ID-Migraine ${ }^{\mathrm{TM}}$. O diagnóstico de cefaleia foi feito de acordo com os critérios da ICHD-2. Resultados: Dos 232 pacientes, $86 \%$ tinham enxaqueca. O questionário apresentou sensibilidade de 92\% (IC de 95\% 88\% a 95\%), especificidade de 60\% (IC de 95\% 43\% a 77\%) e valor positivo preditivo positivo de 93\% (IC 95 89\% a 96\%). Discussão: Nossos resultados foram similares a outros estudos mundiais de aplicação do ID-Migraine ${ }^{\mathrm{TM}}$. A versão em Português é considerada de fácil utilização, sendo uma ferramenta adequada para triagem diagnóstica de migrânea em nossa amostra. Conclusão: Considerando as características do nosso sistema de saúde, podemos inferir que este questionário seria útil nos serviços primários de saúde brasileiros, porém mais estudos são necessários.

Palavras-chave: transtornos de enxaqueca; inquéritos e questionários; cefaleia.

Headache is a major worldwide health problem and the second most common type is migraine, with a global prevalence among adults greater than $10 \%$. Migraine mainly affects adults between 25 and 55 years, during the most productive years of life ${ }^{1}$. In Brazil, the prevalence of migraine is estimated to be $15.2 \%^{2}$.

Lipton et al. ${ }^{3}$ demonstrated that migraine is still underdiagnosed and inappropriately treated. They evaluated 4,376individuals with headache through a computer-assisted telephone interview survey and 536 individuals had migraine, as defined by the International Classification of Headache Disorders - 2nd edition ${ }^{4}$ (ICHD-2). They found that $48 \%$ of migraine sufferers had seen a doctor for headache within the last year and $73 \%$ of these reported a physician-made diagnosis of migraine. Of all migraine sufferers, $49 \%$ were treated with over-the-counter medications, $23 \%$ with prescription medication, $23 \%$ with both, and $5 \%$ with no medications at all ${ }^{3}$.

A study by Bigal et al. ${ }^{5}$ with 6,006 participants, conducted in the State of São Paulo, Brazil revealed that migraine was the most prevalent primary headache, accounting for $45.1 \%$ of patients reporting headache as their only symptom. In another Brazilian study, the correct diagnosis of migraine by non-specialists was made in only $44.9 \%$ of migraine sufferers,

\footnotetext{
1 Universidade Federal Fluminense, Hospital Universitário Antônio Pedro, Ambulatório de Cefaleia, Niterói RJ, Brasil;

${ }^{2}$ Universidade Federal Fluminense, Departamento de Neurologia, Niterói RJ, Brasil;

${ }^{3}$ Faculdade de Medicina de Barbacena, Departamento de Neurologia, Barbacena MG, Brasil;

${ }^{4}$ Universidade Federal Fluminense, Instituto de Matemática e Estatística, Niterói RJ, Brasil.
}

Correspondence: Ana Carolina Musser T. de Mattos; Setor de Pós-graduação em Neurologia; Rua Marques do Paraná, 303 / 4 andar (anexo); $24033-900$ Niterói RJ, Brasil; E-mail:ana_musser@hotmail.com

Conflict of interest: There is no conflict of interest to declare.

Received 16 August 2016; Received in final form 18 March 2017; Accepted 30 March 2017. 
suggesting that improvements in headache treatment may be ineffective unless educational programs improve headache knowledge ${ }^{6}$.

The inadequate medical ability to diagnose and treat migraine has major consequences. Some of the possible outcomes are frequent care visits at outpatient and emergency departments ${ }^{5}$, higher risk of symptomatic medication overuse and subsequent medication-overuse headache ${ }^{7}$ and needless referrals from general practice to neurological outpatient clinics $^{8}$.

Considering incapacity, migraine is the 10th most common cause of "years lived with a disability" in females". Moreover, there is a frequent coexistence of psychiatric illnesses, particularly depression and anxiety, increasing job absenteeism and migraine chronification ${ }^{10}$. Also, due to its chronic nature, including episodic attacks that vary in severity and symptomatology, migraine leads to a reduction in quality of life $\mathrm{e}^{11}$ and to a rise in direct and indirect $\operatorname{costs}^{12,13}$.

The ID-Migraine ${ }^{\mathrm{TM}}$ questionnaire was designed to establish the validity and reliability of a brief, self-administered migraine screening tool for patients with headache complaints, attending the primary care setting. The authors analyzed nine diagnostic screening questions, resulting in a three-item subset comprising disability, nausea, and sensitivity to light. These three questions together provided optimum performance, with a sensitivity of $81 \%$ (95\%CI, $77 \%$ to $85 \%$ ), a specificity of $75 \%$ (95\%CI, $64 \%$ to $84 \%$ ), and positive predictive value (PPV) of 93\% (95\%CI, 89\% to 95\%). Test-retest reliability was good, with a kappa of 0.68 (95\%CI, 54\% to $82 \%$ ) and the Cronbach alpha for the total scale was 0.70 . The author concluded that ID-Migraine ${ }^{\mathrm{TM}}$ was a valid and reliable screening tool for migraine, improving migraine recognition in primary care $^{14}$.

This questionnaire was validated in French ${ }^{15}$, Italian ${ }^{16}$, Turkish $^{17}$ and Portuguese ${ }^{18}$. The latter study was performed in Portugal and showed a sensitivity of 94\% (95\%CI, $87 \%$ to $97 \%$ ), specificity of $60 \%$ (95\%CI, $46 \%$ to $73 \%$ ) and a PPV of $80 \%$ (95\%CI, $71 \%$ to $87 \%)^{18}$. The authors concluded that the Portuguese version of ID-Migraine ${ }^{\mathrm{m}}$ is a valid screening tool for migraine.

A systematic review with extensive meta-analysis was conducted to determine the accuracy of the diagnosis of migraine, using the ID-Migraine $\mathrm{T}^{\mathrm{TM}}$ as a decision tool for identifying migraine sufferers. Thirteen studies with 5,866 patients were included and the questionnaire was shown to be useful for ruling out, rather than ruling in, migraine, with a sensitivity of $84 \%$ (95\%CI, $75 \%$ to $90 \%)$ and a specificity if $76 \%$ (95\%CI, $69 \%$ to $83 \%$ ). The authors considered ID-Migraine $^{\mathrm{TM}}$ to be a brief, practical, and easy-to-use diagnostic tool for migraine in various clinical settings ${ }^{19}$.

The objective of our study was to analyze the applicability of the Portuguese version of ID-Migraine ${ }^{\mathrm{TM}}$ in a sample of Brazilian patients attending the Headache Outpatient Clinic of Antonio Pedro University Hospital.

\section{METHODS}

\section{Patients}

This was a cross sectional study that was approved by the local Ethics Committee. The Portuguese version of ID-Migraine $^{\mathrm{TM}}$, developed by Gil-Gouveia and Martins ${ }^{18}$, was used without modifications (Table 1).

The participants were recruited among adults from the Headache Outpatient Clinic of the Antonio Pedro University Hospital over a 13-month period, reporting at least two headache attacks in the previous three months. Reasons for ineligibility included patients with headache syndromes with no clear diagnosis or not fulfilling definite ICHD-2 diagnostic criteria, psychiatric disorder, secondary headache (except medication-overuse headache) and illiteracy. We also excluded individuals with cognitive deficits (dementia or intellectual disability) or disorders that could interfere in the oral communication (dysphasia, aphasia, deafness or sensory perceptive alterations). All patients signed an informed consent before entering the study. This study was conducted according to the principles expressed in the Declaration of Helsinki.

\section{Clinical protocol}

The Portuguese version of the ID-Migraine ${ }^{\mathrm{TM}}$ questionnaire was administered to the patients and a total score of $\geq 2$ points was considered a positive diagnostic test. Subsequently, they underwent a standard clinical evaluation with complete medical and neurological history and examination. Finally, two neurologists, specialized in headache

Table 1. Original and Portuguese version of ID-Migraine ${ }^{\mathrm{TM}}$

\section{Original $^{14}$}

During the last three months, have you ever had any of the following symptoms concerning your headache pain?

1. Did you ever feel nauseous when you had headache pain?

2. Did the light trouble you (much more than then when there is no headache)?

3. Did your headache ever limit your ability to work, study or do something you needed to, for at least one day?
Portuguese version ${ }^{18}$

Durante os últimos 3 meses, ocorreu algum dos seguintes sintomas com as suas dores de cabeça:

1. Sentiu-se nauseada (o) mal disposta (o) enquanto estava com dor de cabeça?

2. A luz incomodou-a (o) (muito mais do que quando não tem dor de cabeça)?

3. As suas dores de cabeça limitaram a sua capacidade de trabalhar, estudar, ou fazer o que precisava de fazer durante, pelo menos, um dia? 
medicine, blinded to the previous evaluation, confirmed the headache diagnosis based on the ICHD-2 criteria.

\section{Statistical analysis}

The individuals were divided into two groups: Migraine, and Other Headache Types. Patients with migraine (with or without aura) were categorized as "Migraine". Descriptive statistics were performed and results are presented as sensitivity, specificity and PPV measures. All other types of headache were included in the "Other Headache Types" group. The Wilcoxon Rank-Sum test and the Chi-Square test were used for the analysis of categorical variables. Analyses were performed using S-plus v8.0.

\section{RESULTS}

The study group consisted of 232 individuals ( $82 \%$ women), aged $48.9 \pm 11.2$ years (Figure 1 ).
Considering the ICHD-2 criteria, migraine was diagnosed in 199 (86\%) of the patients ( $86 \%$ women). Sixty-three $(31,6 \%)$ had aura. The average age of the "Migraine" group was $40.9 \pm 11.2$ years.

Thirty-three patients (14\%) were included in the "Other Headache Types" group: 17 with tension-type headaches and the remaining with cluster headache, cervicogenic headache, medication-overuse headache and post-traumatic headache.

\section{ID-Migraine ${ }^{\mathrm{TM}}$ analysis}

As shown in Figure 2, of the 199 patients in the "Migraine" group, 168 answered "Yes" to the first question (regarding nausea), 174 answered "Yes" to the second question (regarding photophobia) and 175 answered "Yes" to the third question, regarding disability $(\mathrm{P}<.001)$. Of the 33 individuals in the "Other Headaches Types" group, a positive answer given to the questions were 9, 15 and 14 , respectively.

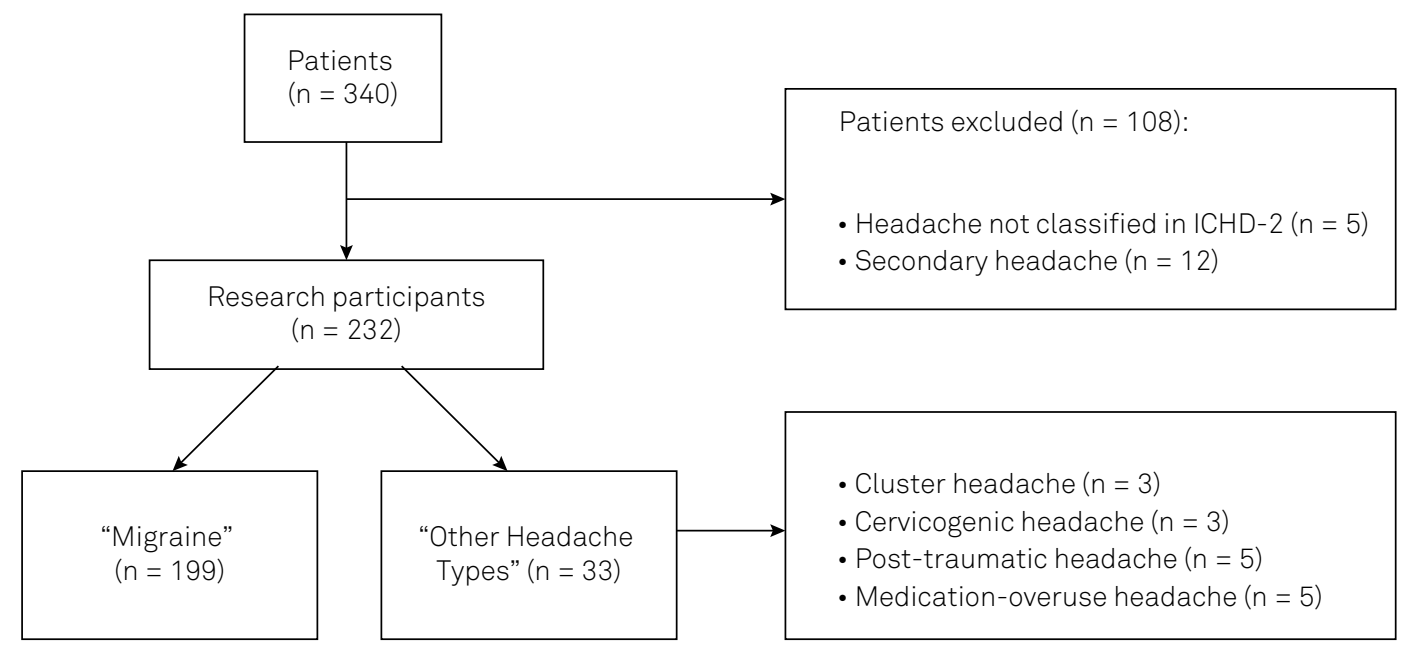

Figure 1. Flowchart of the study.

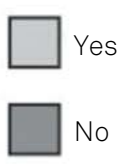

No
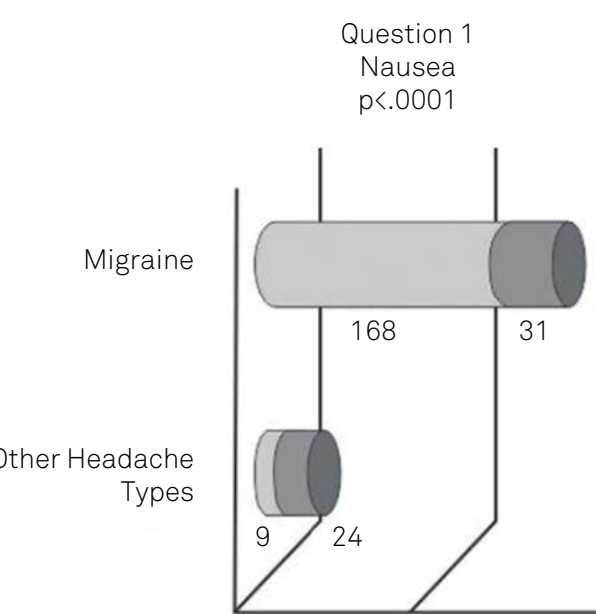

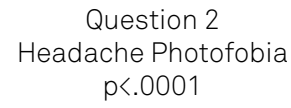

Question 3 Disability $p<.0001$

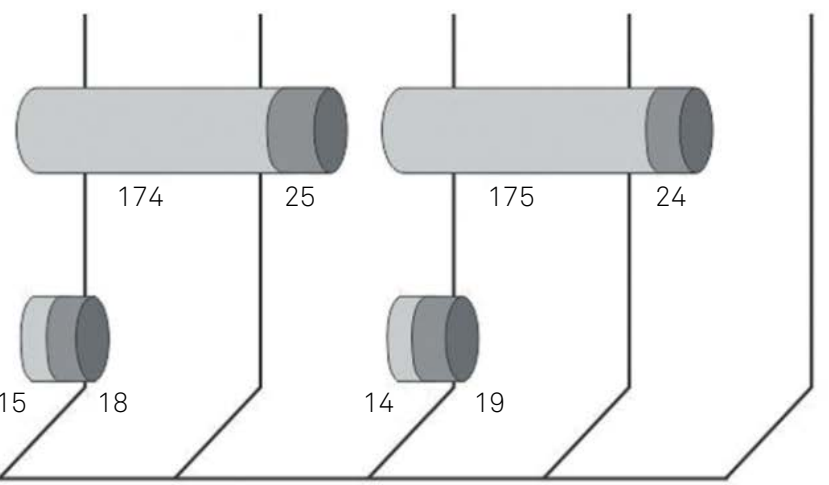


Considering both groups, the amount of "Yes" answers in the three questions was higher in the "Migraine" group, with 92\% (183/199) of the patients giving two or more positive answers in the ID-Migraine ${ }^{\mathrm{TM}}$ questionnaire. In the "Other Headache Types”, 39\% (13/33) had this pattern $(\mathrm{P}<.00001)$. The median of "Migraine" group was two points higher than in the "Other Headache Types" group.

In this specific population, the ID-Migraine ${ }^{\mathrm{TM}}$ showed a sensitivity of $92 \%$ (95\% CI, $88 \%$ to $95 \%$ ), specificity of $60 \%$ (95\% CI, 43\% to $77 \%$ ) and PPV of 93\% (95\% CI, 89\% to 96\%).

\section{DISCUSSION}

The ID-Migraine ${ }^{\mathrm{TM}}$ questionnaire has already been applied in several medical settings. As demonstrated in an extensive meta-analysis by Cousins et al. ${ }^{19}$, the sensitivity of the method was higher than $80 \%$ in all studies, implying that this questionnaire is a good tool for general physicians to improve migraine diagnosis in clinical practice.

In our study, we found a high sensitivity of $92 \%$ (95\%CI, $88 \%$ to 95\%), supporting the Portuguese version of ID-Migraine ${ }^{\mathrm{TM}}$ as a valid and easy-to-use screening tool for migraine diagnosis. We also obtained a PPV of 93\% (95\%CI, 89\% to 96\%) and we relate this to the large number of people with migraine in our sample (199/232).

In Table 2, we compare our results with other worldwide studies using the ID-Migraine ${ }^{\mathrm{TM}}$ as a screening tool. Considering the validated versions in Italian $^{16}$, Turkish ${ }^{17}$ and Portuguese ${ }^{18}$ (Portugal), our results were very similar. Comparing our study to the French ${ }^{15}$ version, the most important difference was their specificity of $100 \%$, while ours was $60 \%$. We relate this high specificity to the sample of healthy subjects from the general population used by the French study. It is unlikely that individuals without headache would give positive answers to the questions of the ID-Migraine ${ }^{\mathrm{TM}}$ as these are highly typical complaints of migraine sufferers and also diagnostic criteria for migraine - based on the gold standard of the ICHD-2.

Our study has a slightly higher sensitivity and lower specificity compared to the original English version ${ }^{14}$ but without major differences. The authors believe that this may be the result of different settings of evaluation as the original work was performed predominantly in primary care. In our study and the others previously cited, the patients were from tertiary care centers. This may be considered a limitation of our study as, in our country, patients with neurological diseases are frequently referred to a tertiary care unit.

Comparing our work with the Portuguese version ${ }^{18}$, we consider it improbable that there were linguistic interferences caused by the use of the Portuguese language spoken in Portugal. We found similar results to the Gil-Gouveia study, with a sensitivity of $92 \%$ vs. $94 \%$, a specificity of $60 \%$ in both, and a PPV of $93 \%$ vs. $80 \%$, respectively. Furthermore, the questions of the questionnaire were very simple and none of the interviewed patients demonstrated difficulty in understanding.

In conclusion, the Portuguese version of ID-Migraine ${ }^{\mathrm{TM}}$ had good applicability in our sample of Brazilian patients, with a prompt application, easy comprehension and a high sensitivity. This questionnaire may help improve the diagnosis of migraine, a common disorder that is still underdiagnosed and considered a troublesome condition in our country, with considerable personal and societal consequences.

Considering the characteristics of our health system, we can infer that this questionnaire would be beneficial in the primary care setting, encouraging generalist practitioners to make a correct diagnosis of migraine. Our results suggest that the application of ID-Migraine $^{\mathrm{TM}}$ is useful and could be applied safely in general practice units, as individuals studied here were assisted originally in primary care, and subsequently referred to a tertiary neurology service. However, more studies in this field are necessary to confirm this hypothesis.

Table 2. Published analyzed measures of the ID-Migraine ${ }^{\text {TM. }}$.

\begin{tabular}{|c|c|c|c|}
\hline \multirow{2}{*}{ Publish } & Sensitivity & Specificity & PPV \\
\hline & $(95 \% \mathrm{Cl})$ & $(95 \% \mathrm{Cl})$ & $(95 \% \mathrm{Cl})$ \\
\hline \multirow{2}{*}{ English (original) ${ }^{14}, 2003$} & $81 \%$ & $75 \%$ & $93 \%$ \\
\hline & $(77 \%$ to $85 \%)$ & $(64 \%$ to $84 \%)$ & (90\% to $96 \%)$ \\
\hline \multirow{2}{*}{ Italian ${ }^{16}, 2007$} & $95 \%$ & $72 \%$ & $88 \%$ \\
\hline & (91\% to $98 \%)$ & (62\% to $82 \%)$ & (82\% to $93 \%)$ \\
\hline \multirow{2}{*}{ Turkish ${ }^{17}, 2007$} & $92 \%$ & $63 \%$ & $72 \%$ \\
\hline & $\mathrm{NI}$ & $\mathrm{NI}$ & $\mathrm{NI}$ \\
\hline \multirow{2}{*}{ Portuguese ${ }^{18}, 2008$} & $94 \%$ & $60 \%$ & $80 \%$ \\
\hline & (87\% to $97 \%$ ) & (46\% to $73 \%)$ & (71\% to $87 \%)$ \\
\hline \multirow{2}{*}{ Cousins et a.. $1^{19}, 2011$} & $84 \%$ & $76 \%$ & \multirow{2}{*}{$\mathrm{NI}$} \\
\hline & (75\% to $90 \%)$ & (69\% to $83 \%)$ & \\
\hline \multirow{2}{*}{ French $^{15}, 2015$} & $87 \%$ & $100 \%$ & $100 \%$ \\
\hline & (74\% to $100 \%)$ & (91\% to $100 \%)$ & (82\% to $100 \%)$ \\
\hline \multirow{2}{*}{ Authors, 2016} & $92 \%$ & $60 \%$ & $93 \%$ \\
\hline & (88\% to $95 \%)$ & (43\% to $77 \%)$ & (89\% to $96 \%$ ) \\
\hline
\end{tabular}


1. Stovner L, Hagen K, Jensen R, Katsarava Z, Lipton R, Scher A et al. The global burden of headache: a documentation of headache prevalence and disability worldwide. Cephalalgia. 2007;27(3):193-210 https://doi.org/10.1111/j.1468-2982.2007.01288.x

2. Queiroz LP, Peres MF, Piovesan EJ, Kowacs F, Ciciarelli MC, Souza JA et al. A nationwide population-based study of migraine in Brazil. Cephalalgia. 2009;29(6):642-9. https://doi.org/10.1111/j.1468-2982.2008.01782.x

3. Lipton RB, Scher Al, Kolodner K, Liberman J, Steiner TJ, Stewart WF. Migraine in the United States: epidemiology and patterns of health care use. Neurology. 2002;58(6):885-94. https://doi.org/10.1212/WNL.58.6.885

4. The International Headache Society. The international classification of headache disorders: 2nd edition. Cephalalgia. 2004;24(Suppl. 1):9-160.

5. Bigal ME, Bordini CA, Speciali JG. Etiology and distribution of headaches in two Brazilian primary care units. Headache. 2000;40(3):241-7. https://doi.org/10.1046/j.1526-4610.2000.00035.x

6. Vincent MB, de Carvalho JJ. Primary headache care delivery by nonspecialists in Brazil.. Cephalalgia. 1999;19(5):520-4. https://doi.org/10.1046/j.1468-2982.1999.019005520.x

7. Diener HC, Limmroth V. Medication-overuse headache: a worldwide problem. Lancet Neurol. 2004;3(8):475-83. https://doi.org/10.1016/S1474-4422(04)00824-5

8. Bekkelund SI, Albretsen C. Evaluation of referrals from general practice to a neurological department. Fam Pract. 2002;19(3):297-9. https://doi.org/10.1093/fampra/19.3.297

9. Mathers CD, Bernard C, Iburg KM, Inoue M, Fat DM, Shibuya Ket al. Global Burden of Disease in 2002: data sources, methods and results. 2004 [cited year month day] . Available from: http://www.who.int/ healthinfo/paper54.pdf

10. Antonaci F, Nappi G, Galli F, Manzoni GC, Calabresi P, Costa A. Migraine and psychiatric comorbidity: a review of clinical findings. J Headache Pain. 2011;12(2):115-25. https://doi.org/10.1007/s10194-010-0282-4
11. Dahlof CG, Solomon GD. The burden of migraine to the individual sufferer: a review. Eur J Neurol. 1998;5(6):525-33. https://doi.org/10.1046/j.1468-1331.1998.560525.x

12. Edmeads J, Mackell JA. The economic impact of migraine: an analysis is of direct and indirect costs. Headache. 2002;42(6):501-9. https://doi.org/10.1046/j.1526-4610.2002.04262.x

13. Lipton RB, Stewart WF, von Korff M. Burden of migraine: societal costs and therapeutic opportunities. Neurology. 1997;48(3 Suppl 3):S4-9 https://doi.org/10.1212/WNL.48.3_Suppl_3.4S

14. Lipton RB, Dodick D, Sadovsky R, Kolodner K, Endicott J, HettiarachchiJetal.Aself-administered screenerformigraine in primary care: the ID Migraine validation study. Neurology. 2003;61(3):375-82. https://doi.org/10.1212/01.WNL.0000078940.53438.83

15. Streel S, Donneau AF, Dardenne N, Hoge A, Bruyère O, Albert A et al. Validation of an extended French version of ID Migraine ${ }^{\mathrm{TM}}$ as a migraine-screening tool. Cephalalgia. 2015;35(5):437-42. https://doi.org/10.1177/0333102414544910

16. Brighina F, Salemi G, Fierro B, Gasparro A, Balletta A, Aloisio A et al. A validation study of an Italian version of the "ID Migraine". Headache. 2007;47(6):905-8. https://doi.org/10.1111/j.1526-4610.2006.00628.x

17. Karli N, Ertas M, Baykan B, Uzunkaya O, Saip S, Zarifoglu M et al. The validation of ID Migraine screener in neurology outpatient clinics in Turkey.J Headache Pain. 2007;8(4):217-23. https://doi.org/10.1007/s10194-007-0397-4

18. Gil-Gouveia R, Martins I. Validation of the Portuguese version of ID-Migraine. Headache. 2010;50(3):396-402. https://doi.org/10.1111/j.1526-4610.2009.01449.x

19. Cousins G, Hijazze S, Van de Laar FA, Fahey T. Diagnostic accuracy of the ID Migraine: a systematic review and meta-analysis. Headache. 2011;51(7):1140-8. https://doi.org/10.1111/j.1526-4610.2011.01916.x 